\title{
Bicipitoradial Bursitis in a Patient With Behçet's Disease
}

\author{
Won Ho Choi, M.D., Jong-Sun Kim, M.D., Kyung-Ann Lee, M.D., Ph.D., Hyun-Sook Kim, M.D., Ph.D. \\ Division of Rheumatology, Department of Internal Medicine, Soonchunhyang University Seoul Hospital, Seoul, Korea
}

\begin{abstract}
A 36-year-old man, with abrupt onset of right elbow pain without trauma, visited our clinic. He had been taking prednisolone $2.5 \mathrm{mg} /$ day, colchicine $0.3 \mathrm{mg} /$ day, celecoxib $400 \mathrm{mg} /$ day, and methotrexate $12.5 \mathrm{mg}$ once weekly for Behçet's arthritis for the past 5 years. His elbow pain was aggravated by pronation and supination at the lateral side of the right antecubital area with no palpable mass. Magnetic resonance imaging showed cystic fluid collection adjacent to the biceps tendon insertion at the right radial head (Figure 1A). There was a signal change in the biceps tendon near the bicipitoradial bursa beneath the brachioradialis muscle and a thick peripheral rim enhancement in post-contrast images. Ultrasonography defined a bicipitoradial bursa measuring $1.7 \times 1.2 \mathrm{~cm}$ (Figure $1 B)$. With a diagnosis of bicipitoradial bursitis, we in-
\end{abstract}

creased the dose of prednisolone and recommended that he rest his right arm. Two weeks later, the pain had subsided and the enlarged bursa had completely disappeared in ultrasonography (Figure 1C). Bicipitoradial bursitis is a rare pathological condition in the cubital fossa of the elbow which results from repetitive mechanical trauma, infection, chemical synovitis and inflammatory arthritis [1-3]. When the superficial branch of the radial nerve is compressed by the bursa enlargement it creates pain, and is often reported in cases of inflammatory arthritis such as rheumatoid arthritis and spondyloarthritis [4]. Bicipitoradial bursitis should be considered in Behçet's arthritis patients with a complaint of atypical elbow pain.
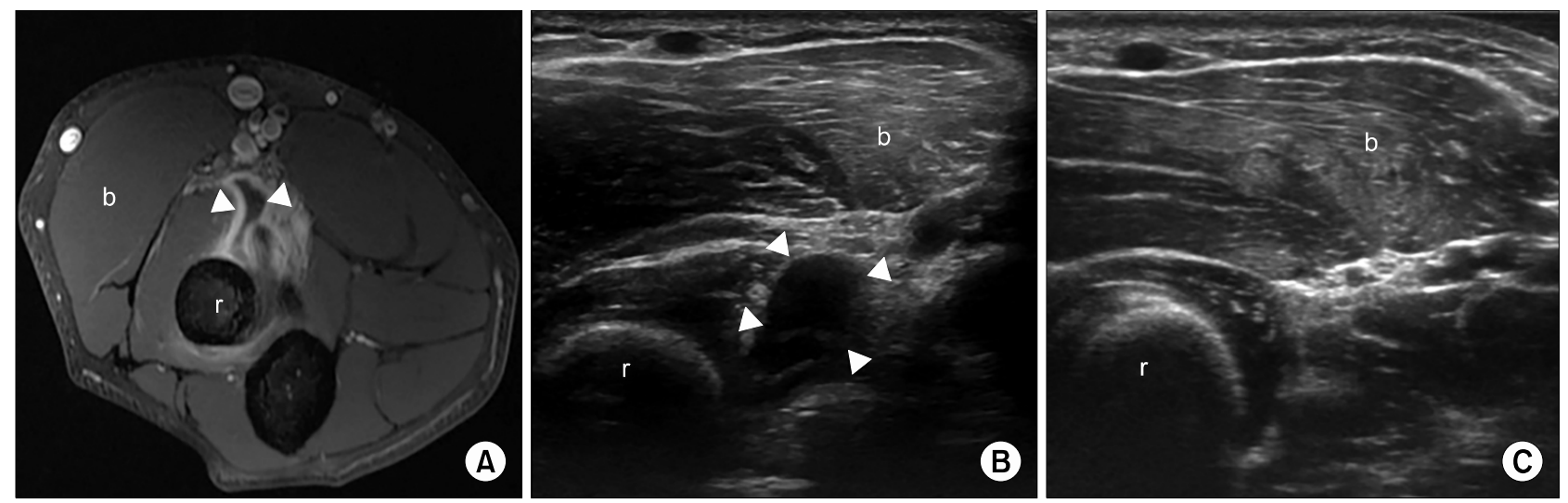

Figure 1. Magnetic resonance imaging showed cystic fluid collection adjacent to the biceps tendon insertion at the right radial head. There was a signal change in the biceps tendon near the bicipitoradial bursa beneath the brachioradialis muscle and a thick peripheral rim enhancement in post-contrast images (A). Ultrasonography defined a bicipitoradial bursa measuring $1.7 \times 1.2 \mathrm{~cm}$ (B). Two weeks later, the enlarged bursa had completely disappeared in ultrasonography (C). r: radial head, b: brachioradialis muscle, arrowheads: bicipitoradial bursa.

Received : July 21, 2020, Revised : August 2, 2020, Accepted : August 7, 2020

Corresponding to : Hyun-Sook Kim (1D http://orcid.org/0000-0001-9213-7140

Division of Rheumatology, Department of Internal Medicine, Soonchunhyang University Seoul Hospital, 59 Daesagwan-ro, Yongsan-gu, Seoul 04401, Korea. E-mail : healthyra@schmc.ac.kr

Copyright (C) 2021 by The Korean College of Rheumatology.

This is an Open Access article, which permits unrestricted non-commerical use, distribution, and reproduction in any medium, provided the original work is properly cited. 


\section{ACKNOWLEDGMENTS}

This study was supported by funding from Soonchunhyang University.

\section{CONFLICT OF INTEREST}

No potential conflict of interest relevant to this article was reported.

\section{AUTHOR CONTRIBUTIONS}

Conceptualization: W.H.C., H.S.K. Data curation: J.S.K., K.A.L. Writing-original draft: W.H.C., K.A.L. Writing- re- view \& editing: W.H.C., H.S.K.

\section{REFERENCES}

1. Karanjia ND, Stiles PJ. Cubital bursitis. J Bone Joint Surg Br 1988;70:832-3.

2. Liessi G, Cesari S, Spaliviero B, Dell'Antonio C, Avventi P. The US,CT and MR findings of cubital bursitis: a report of five cases. Skeletal Radiol 1996;25:471-5.

3. Ng C, Bibiano L, Grech S, Magazinovic B. Antecubital fossa solitary osteochondroma with associated bicipitoradial bursitis. Case Rep Orthop 2015;2015:560372.

4. Ter Borg EJ, Bollen T. Isolated bicipito-radial bursitis in a patient with rheumatoid arthritis. J Clin Rheumatol 2018;24:97. 